\title{
Effect of Groundnut Shell Powder on the Mechanical Properties of Recycled Polyethylene and Its Biodegradability
}

\author{
Mohammed Awwalu Usman ${ }^{1 *}$, Ibrahim Momohjimoh ${ }^{2}$, Abdulahi S. B. Gimba ${ }^{3}$ \\ ${ }^{1}$ Department of Chemical Engineering, University of Lagos, Lagos, Nigeria \\ ${ }^{2}$ Department of Metallurgical Engineering, Yaba College of Technology, Lagos, Nigeria \\ ${ }^{3}$ Skilia Resources Ltd., Abuja, Nigeria \\ Email: *mawwal04@yahoo.com,oseke2@gmail.com,dr.abdullahi.gimba@gmail.com
}

Received 2 March 2016; accepted 27 May 2016; published 30 May 2016

Copyright (C) 2016 by authors and Scientific Research Publishing Inc.

This work is licensed under the Creative Commons Attribution International License (CC BY). http://creativecommons.org/licenses/by/4.0/

(c) (i) Open Access

\begin{abstract}
Natural fiber reinforced composites have gained considerable attention particularly in the manufacturing industry owing to their light weight, corrosion resistance, abundance, and biodegradability. In this work, alkaline treated and untreated groundnut shell powder (GSP) was used to reinforce recycled polyethylene to produce GSP-recycled polyethylene composites with improved mechanical properties and biodegradability. GSP with particle sizes of $0-300 \mu \mathrm{m}$ and $300-600 \mu \mathrm{m}$ was used in different proportions: $5 \%, 10 \%, 15 \%, 20 \%, 25 \%$, and $30 \%$ wt. The fiber was immersed for 5 hours in a 10 wt\% NaOH solution. Tensile and hardness test data showed an improvement in mechanical properties of the treated fiber composites. Results of water absorption test also showed that treated GSP-recycled polyethylene composites had a lower rate of water absorption than the untreated GSP-recycled polyethylene composites. Through Fourier transform infrared spectroscopy, disappearance of characteristics peaks of hemicellulose and lignin was observed. Growth of fungi on the fiber-reinforced composites was observed, which was evidence that GSP-recycled polyethylene composite was biodegradable. Finally, SEM micrographs showed uniform distribution of treated fibers in the polymer matrix; this explained the observed improvement in the mechanical properties of treated GSP-recycled polyethylene composites.
\end{abstract}

\section{Keywords}

Groundnut Shell Powder, Fibers, Recycled Polyethylene, Composites, Mechanical Properties, Biodegradability

\footnotetext{
${ }^{*}$ Corresponding author.
} 


\section{Introduction}

Polyethylene (PE) has semicrystalline structure with roughly equal parts of crystalline and amorphous domains due to the orientation of the methylene main chain [1]; vastly used in industrial applications because of their mechanical properties [2]. The precise degree of crystallinity and density are dependent on the molecular weight $(\mathrm{Mw})$ of PE, giving rise to classification into low-density PE (LPDE, Mw $\approx 50,000$ ), high density PE (HDPE, $\mathrm{Mw} \approx 200,000$ ) and ultrahigh molecular weight PE (UHPE, $\mathrm{Mw} \approx 3,500,000-7,500,000$ ) [3]. LDPE shows a degree of crystallinity in the range of $40 \%-50 \%$ owing to high level of long chain branching that partially obstructs folding and alignment of the methylene chain [4]. Consequently, LPDE exhibits excellent performances such as opacity, tensile strength, tear strength, rigidity modulus, chemical resistance and flexibility even at a low temperature. It is a low-cost material with good processability, excellent electrical insulation properties, chemical resistance, high toughness and flexibility even at a low temperature [5]. Generally, PE is the most widely used polymer in various packaging and functional applications with a reported annual production of $80 \mathrm{M}$ tons in 2007 [3] [6]. In Nigeria, LPDE is enjoying ubiquitous use for packaging pure water; resulting in large volumes of waste. This constitutes serious environmental challenge since it is non-biodegradable as attested by several studies [7]-[12].

Recycling is a preferable method of addressing this environmental challenge due to the low melting point and ease of processing on conventional equipment coupled with its relatively cheap nature [13]. However, recycling is dogged with the disadvantage of degradation and deterioration in the mechanical, thermal and other relevant properties. There is therefore the need to improve these properties in order to make recycling PE worthwhile. Equally important is the need to enhance the biodegradability of the recycled PE to facilitate its eventual disposal to the environmental after several cycles. Natural fibers have proved to be invaluable on both counts when used as reinforcing filler in the polymer matrix. Several natural fibers have been investigated in this regard including coir fiber [14], wood fiber [15]-[17], rice straw fiber [18], sisal fiber [19], hemp fiber [20], banana flour [21], olive stone flour [22], kenaf fiber [23] and chitosan [24].

Groundnuts (Arachis hypogea) is one of the most common commercial crops in Nigeria which account for 70\% of the total Nigeria export earning between 1955 and 1967; its production in Nigeria in 2002 was estimated to be 23,390,000 million tons [25]. In another report, Nigeria was said to be the third world largest producer of groundnut in 2011, producing 2,962,760 tons behind China and India which produce 16,114,231 and 6,933,000 tons, respectively [26]. A phenomenal increase in production of groundnut is expected in the very near future owing to the current agricultural initiative of the Nigerian government as part of a holistic diversification drive in the face of plummeting crude oil price. Alaneme et al. [27] predicted an increased production capacity of 120,000 metric tons in the next few years. Groundnut shell is a waste product obtained after the removal of groundnut seed from its pod, and there has not been considerable demand for the utilization of groundnut shell for the benefit of mankind. Groundnut shell is a lignocellulosic waste or natural fiber that can be used as reinforcing filler in polymer composite. However, there is limited study on its application in this regard in the literature. Recently, Alaneme et al. [27] reported on the use of groundnut shell ash (obtained from combustion of groundnut shell) in conjuction with silicon carbide as hybrid reinforcements in the development of Al-Mg-Si composites for improved corrosion resistance and mechanical properties. In Nigeria, groundnut shell is presently not put to any valuable use despite its huge quantity, thus constituting environmental waste disposal issue even though it is biodegradable. A potential valorization of groundnut shell is its possible use as reinforcing filler in polymer matrix. Groundnut shell powder (GSP)-recycled polyethylene composite has the prospect of combining good mechanical properties with low specific mass and is expected to find use in automobile as car bumper and in food processing industry as food take way packs.

In order to address the weak interfacial adhesion between natural fibers and polymer matrices, a number of fiber surface modification techniques have been developed to improve the interfacial bond strength and are classified into two groups: conventional or chemical treatment and environment or green approach treatment methods [28]. Chemical methods include mercerization, acetylation, peroxide, benzoylation, coupling agents and polymer grafting while environmental treatment methods include treating fibers with plasma, enzyme, fungi and coating with cellulose. Chemical methods of treatments are easily processable, useful and acceptable in varieties of applications, highly implemented at industrial scale, low cost, short treatment time and with greater flexibility [29]-[33]. Alkaline treatment of cellulosic fibers with sodium hydroxide is a well-known method which has been employed to improve fiber-polymer matrix interfacial bonding [34]. This treatment reduces the hydrophilicity of 
the fibers and increases its hydrophobicity by the removal of natural fats and waxes from cellulosic fibers surfaces. Marques et al. [35] observed that the surface of flax and jute after alkaline treatment became smoother which revealed that low molar mass components such as pectin, hemicelluloses, lignin and other polysaccharides have been removed. Sareena et al. [36] reported that alkali treatment of peanut shell powder (PSP) was more effective for improving the fiber-matrix adhesion as compared to other methods and the tensile strength of PSP-natural rubber composite was found to be higher than untreated PSP-natural rubber composite.

This work is therefore aimed at investigating the possibility of using untreated GSP and alkali treated GSP of two different particle sizes $(0-300 \mu \mathrm{m}$ and $300-600 \mu \mathrm{m})$ with particle loading ranging from $0 \%-30 \%$ as filler in recycled polyethylene matrix and evaluation of their mechanical properties and biodegradability.

\section{Materials and Method}

\subsection{Materials}

The low-density polyethylene was sourced and recycled at the recycling plant in Ojota, Lagos Mainland, Lagos, Nigeria. The groundnut shells were equally sourced locally and then pulverized in Bariga, Lagos, Nigeria. Sodium hydroxide was obtained from the Chemistry Department, University of Lagos, Nigeria and the litmus paper was purchased from Finlab, Palmgrove, Yaba, Lagos, Nigeria.

\subsection{Method}

\subsubsection{Modification of GSP Using Sodium Hydroxide}

One gram of GSP (particle size: 0 - 300 and 300 - $600 \mu \mathrm{m}$ ) was put in a $10 \% 10 \mathrm{~mL} \mathrm{NaOH}$ solution for 5 hours with continuous stirring. It was then rinsed and washed with water until the solution became neutral. The powder was filtered out and dried in vacuum at $80^{\circ} \mathrm{C}$ for 5 hours for further use.

\subsubsection{Preparation of GSP-Recycled Polyethylene Composites}

The consolidation of GSP-recycled polyethylene involves mixing of the recipe and finally compounding it into composites. The mixing was done according to the ASTM method. The two roll mills were switched on and the nip of each roll was tightened before the recycled plastic was fed in between the nips of the rolls and allowed to melt in order to reduce the molecular weight of the plastic. After the plastic had melted and the band was formed round the front roll of the mill in between the nips of the rollers, the filler (peanut shell powder) was fed into the nip of the rolls and cross mixing was done to ensure uniform and homogenous dispersion in the sample. The nips of the rollers were adjusted to a desired thickness and the compounded material was sheeted out before taking it for pressing (shaping).

\subsubsection{Curing}

The curing of the compounded material was done on a hydraulic machine (hot press) with electrically heated platens. The temperature of the platens was set at $140^{\circ} \mathrm{C} \pm 5^{\circ} \mathrm{C}$ and when the temperature was attained, the moulds were preheated to attain the platen temperature. The material was then cut to take the shape of the mould and was placed in between the platen with a pressure of 3 tons for 10 minutes, and finally the cured samples were removed from the mould after cooling. Twenty-five (25) samples were produced for both treated and untreated GSP. The treated sample was denoted as $\mathrm{T}$ while the untreated was denoted as $\mathrm{U}$. The composition of the GSP followed the letter and then the particle size of the GSP in the sample, for instance, T20 300 denote a composite with $20 \%$ treated GSP and particle size 0 - $300 \mu \mathrm{m}$. The sample with zero percent (\%) GSP was denoted as the control sample. The proper description of sample symbol and their corresponding meaning is stated in Table 1.

\subsection{Mechanical Property Test}

\subsubsection{Tensile Test}

The tensile testing of the samples was done at Yaba College of Technology, Lagos, Nigeria in accordance with ASTM D638 standards. The samples were machined to dumbbell shape and then placed in the universal tensile testing machine and the tensile strength was evaluated. 
Table 1. The designation of symbol and their meaning as presented in this work.

\begin{tabular}{|c|c|}
\hline Symbol & Meaning \\
\hline T20 300 & $\begin{array}{l}20 \text { wt } \% \text { Treated groundnut shell powder with particle size in the range of } \\
0 \text { to } 300 \mu \mathrm{m} \text { reinforced recycled polyethylene composite }\end{array}$ \\
\hline T20 600 & $\begin{array}{l}20 \mathrm{wt} \% \text { Treated ground shell powder with particle size in the range of } \\
300 \text { to } 600 \mu \mathrm{m} \text { reinforced recycled polyethylene composite }\end{array}$ \\
\hline U25 300 & $\begin{array}{l}25 \text { wt\% Untreated groundnut shell powder with particle size in the range of } \\
0 \text { to } 300 \mu \mathrm{m} \text { reinforced recycled polyethylene composite }\end{array}$ \\
\hline U20 600 & $\begin{array}{l}20 \text { wt\% Untreated groundnut shell powder with particle size in the range of } \\
300 \text { to } 600 \mu \mathrm{m} \text { reinforced recycled polyethylene composite }\end{array}$ \\
\hline Control & Recycled polyethylene without groundnut shell powder \\
\hline
\end{tabular}

\subsubsection{Hardness Test}

The hardness of the GSP-recycled polyethylene was done in Material Science Lab, Department of Mechanical Engineering, King Fard University, Saudi Arabia in accordance with ASTM D2240 on shore Durometer model: E-Durometer shore digi S1-D using a load of $453 \mathrm{~g}$ and sharp of $30^{\circ}$ angle. Five measurements were performed on each sample at different spots and the average of the values was taken as the hardness of the sample.

\subsection{Water Absorption Test}

The water absorption test was carried out based on ASTM D-570. The samples were cut, cleaned and weighed before immersion in distilled water at room temperature. The specimens were removed from the water after 24 hours and the surface was wiped off and weighed. The difference between the weight before and after immersion was noted. This procedure was repeated every 24 hours for 168 hours (7 days). The percentage water absorption W \% was determined based on the expression (Equation (1)):

$$
W \%=\frac{w_{f}-w_{o}}{w_{o}} \times 100
$$

where $w_{f}$ and $w_{o}$ are the final and initial weights of the samples after and before immersion respectively.

\subsection{Biodegradability Test}

The biodegradability of the sample was tested by inoculating the samples with Aspergillus niger (A. niger) on a potato dextrose agar media and incubated at surrounding temperature $\left(25^{\circ} \mathrm{C}\right)$ for 21 days (Mani and Bhattacharya, 1998). The samples were cut $(2.0 \mathrm{~cm}$ and $2.0 \mathrm{~cm})$ and faced on the surface of mineral salts of agar in a petri dish containing no additional carbon source. Before facing the samples, agar surfaces were cultivated with $A$. niger. After 21 days, the samples were examined for evidence of colony growth.

\subsection{Characterization}

\subsubsection{FTIR Analysis}

The Fourier transform infrared (FTIR) spectrometry was used to identify the chemical structure of GSP (untreated and treated) and GSP-recycled polyethylene composites. The dry sample was blended in a mortar with KBr crystal. Then the mixture was pelletized under a mini hand press or hydraulic press to form a film which was subjected to FTIR analysis.

\subsubsection{Scanning Electron Microscopy (SEM)}

The sample was placed on a carbon tab placed on the SEM sample holder to provide a conducting path for the electron during SEM imaging. Thereafter, the sample was taken for gold coating. The gold coating sample chamber was cleaned before fixing the specimen on studs and the stud with the specimen was kept facing the gold target and it was ensured that the specimen did not touch the cathode ring in the instrument. Cleaning of the gold coating instrument was done with acetone. The O-Ring was replaced in the groove and the glass jar was placed properly on its seat. Then the switch was put on to evacuate the chamber until the pressure indicated 0.1 
atm. The HV switch was turned on, switched to DC and gradually increased to $2 \mathrm{~mA}$. The time was set for 9 minutes so as to increase the thickness of the coating; finally, the sample was removed for SEM analysis. The SEM of the samples was done in the Material Science Lab, Mechanical Engineering Department, King Fard University, Saudi Arabia with SEM machine model: JEOL JSM-6064LV—80 mm sample height-WD48 mm-3.0 $\mathrm{nm}$ resolution $-300,000 \times$ magnification $-\mathrm{SEI} / \mathrm{BEI}$ modes -0.3 to $30 \mathrm{KV}$ accelerating voltage-XYZ and tilting movements. The imaging of the samples was done at $10 \mathrm{KV}$ accelerating voltage and at various magnifications.

\section{Results and Discussion}

GSP-recycled polyethylene composites were produced after compounding and compression and the GSP composition was varied from 5\% - 30\% for both treated and untreated with particle size ranges from 0 - $300 \mu \mathrm{m}$ and $300-600 \mu \mathrm{m}$, respectively. In all, a total of 25 samples were produced including the control sample ( $0 \% \mathrm{GSP})$. However, based on physical observation and mechanical testing, four (4) of the GSP-recycled polyethylene composites were found to have the best properties and all these four samples were further subjected to other tests and the results are reported in this section.

\subsection{Mechanical Property Test}

\section{Tensile Test}

Figures 1-4 shows the results of tensile testing of the GSP-recycled polyethylene composites for fives samples which include untreated (U20 600) 20\% GSP with particle size 300 - $600 \mu \mathrm{m}$, untreated (U25 300) 25\% GSP with particle size 0 - $300 \mu \mathrm{m}$, treated (T20 300) 20\% GSP with particle size 0 - $300 \mu \mathrm{m}$ and treated (T20 600) 20\% GSP with particle size 300 - $600 \mu \mathrm{m}$ and 0\% GSP (control).

In Figure 1, the stress-strain graph of the samples was displayed and it revealed that the tensile strength of the samples increased as a result of treatment of the fibers. Treated sample with the smaller particle size (T20 300) has the highest tensile strength and the strength increases with the strain for all the samples; the control sample has the lowest strength with strain variation.

Figure 2 shows the variation of strength with GSP particle loading. It was discovered that the strength of the GSP-recycled composite increases with increases in particle loading. Furthermore, treated particle GSP-recycled polyethylene composites were found to have higher strength as compared to untreated GSP. This is because the treated samples have higher interfacial bonding which occurred as a result of decrease in the hydrophilicity of the GSP [34] [35]. The particle size also plays a significant role in the strength increment as evident in Figure 1. A comparison of treated samples of different particle sizes, showed that a treated GSP composite (T20 300) has a higher strength of $7.7 \mathrm{MN} / \mathrm{m}^{2}$ than treated GSP composite (T20 600) of $7.2 \mathrm{MN} / \mathrm{m}^{2}$. Similarly, the strength

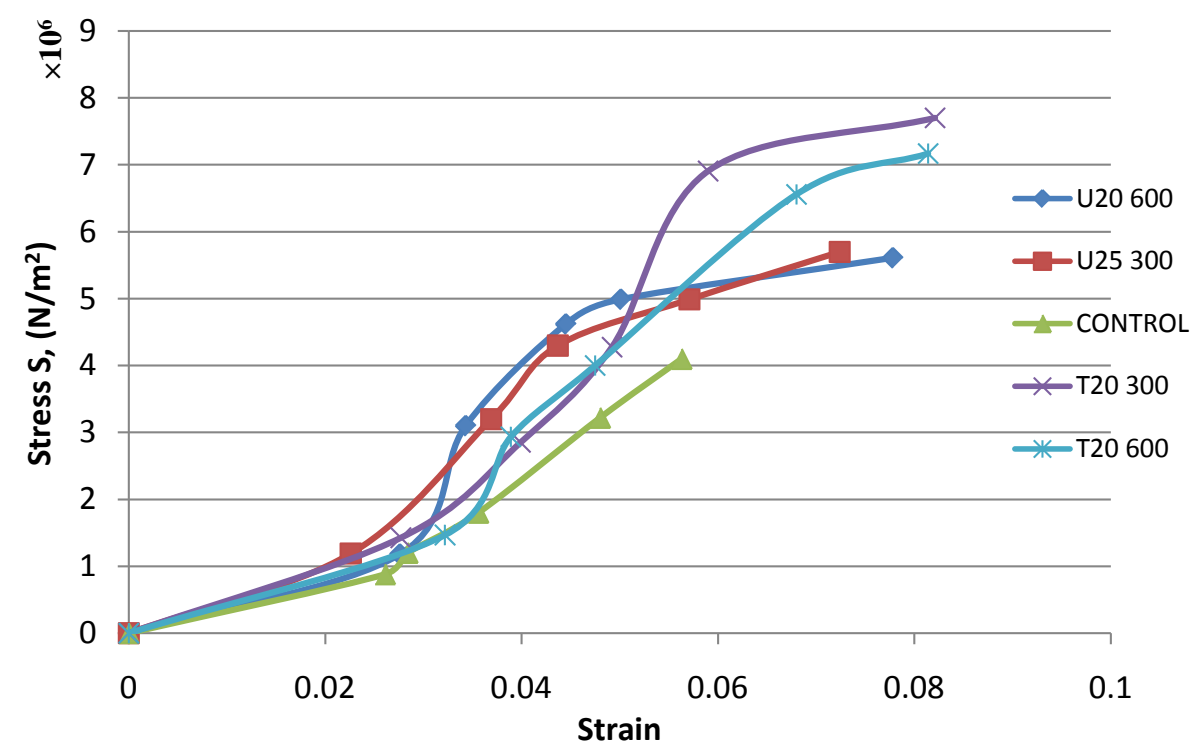

Figure 1. Stress-strain graph of the selected samples with the best properties. 


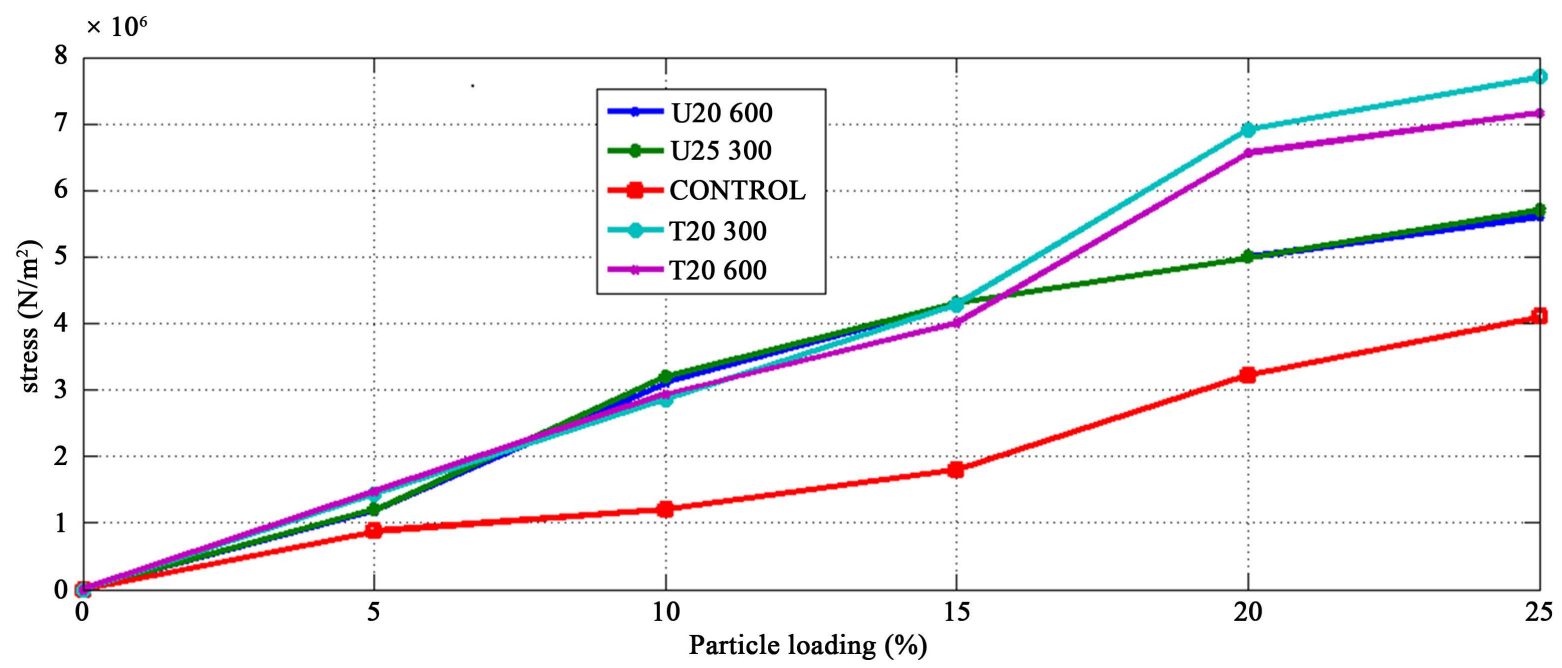

Figure 2. Stress and percentage (GSP) particle loading.

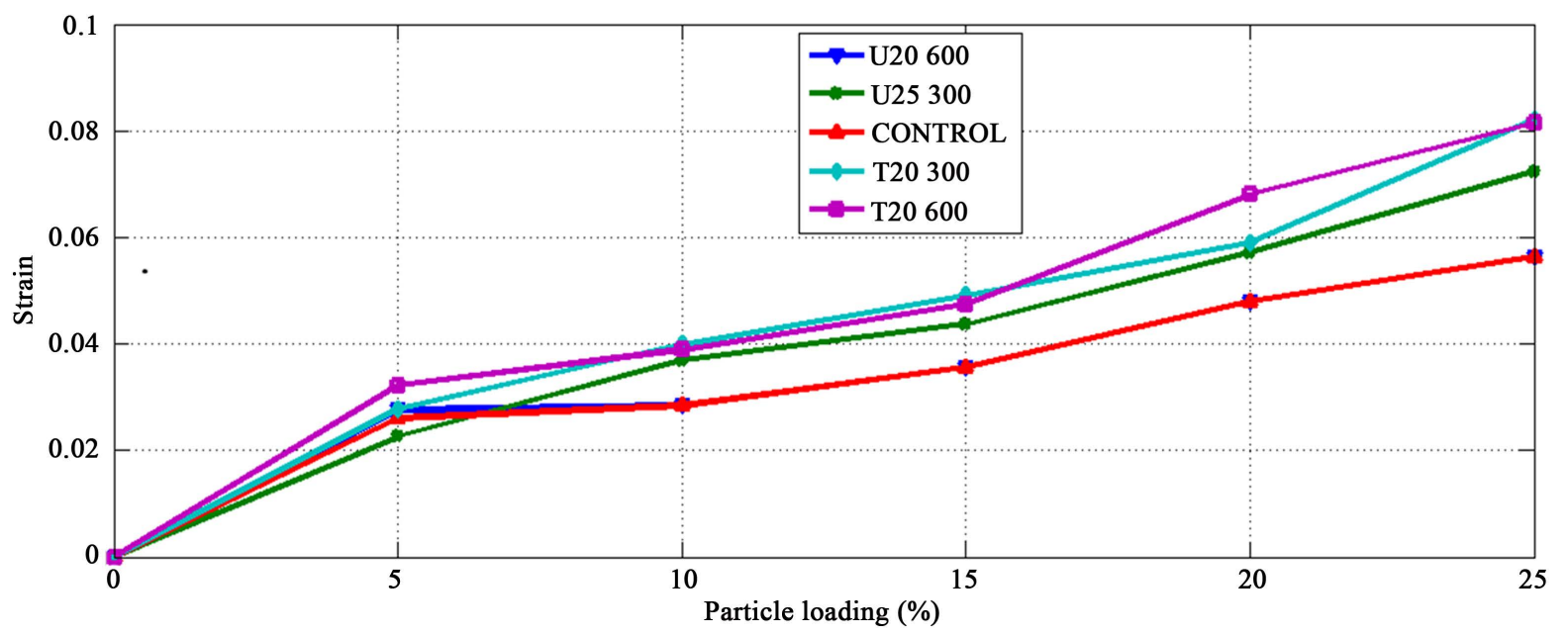

Figure 3. Strain and percentage (GSP) particle loading.

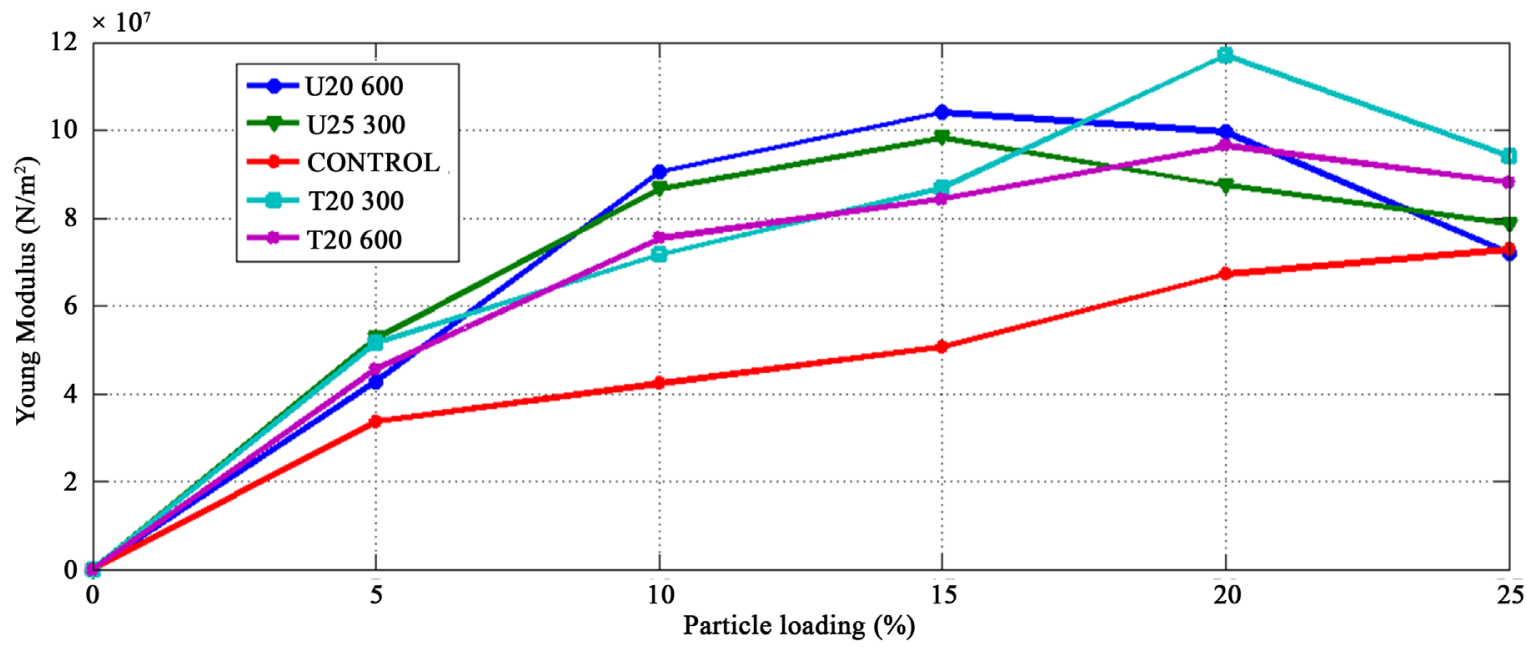

Figure 4. Young Modulus and percentage (GSP) particle loading. 
of the composite is considerably higher than that of control sample ( $0 \%$ GSP) for both treated and untreated samples. Based on the initial observation, the optimal strength of the composite occurred at a particle loading (GSP) of $20 \%$ by weight. Further increase of particle size resulted in the reduction of strength. However, untreated GSP-recycled polyethylene composite (U25 300) of particle size 0 - $300 \mu \mathrm{m}$ was found to have better mechanical properties as compared to the sample (U20 300).

Figure 3 shows strain variation with particle loading and the behaviour of all the samples is similar to what was observed in Figure 2, where with (T20 300) has the highest strain. This was a result of treatment in combination with the particle size of the filler.

Figure 4 shows the Young modulus and particle loading but the behaviour is slightly different from other figures as explained above. Here, untreated GSP-recycled polyethylene composite (U20 600) has the highest Modulus until at $20 \%$ particle loading.

Figure 5 compares the hardness of the composites with the treated (T20 300) having the hardness value of 70.0 shore $\mathrm{D}$. This is because the small amount of voids available in the matrix was almost completely filled up by the particle reinforcement as compared to treated sample of larger particle size (T20 600) whose hardness value is about 55.7 shores D. Again, the hardness of the composites does not follow any particular pattern but it was observed that particle size, as well as particle loading, plays a more significant role than surface treatment.

\subsection{Water Absorption}

Figure 6 shows the rate of water absorption of the composites for the treated, untreated and control samples. The figure shows that the rate of water absorption is highest in the treated (T20 600) followed by the control sample. This result is contrary to expectation, as composites with fiber reinforcement, whether treated or untreated, should exhibit higher water absorption due to the inherent hydrophilic nature of the filler [22] [30] [37][41]. However, water absorption depends on several factors, namely the type of fiber, its loading and orientation, area of exposed surface, interfacial adhesion, voids, and surface protection [41] [42]. Sample (T20 600) and the

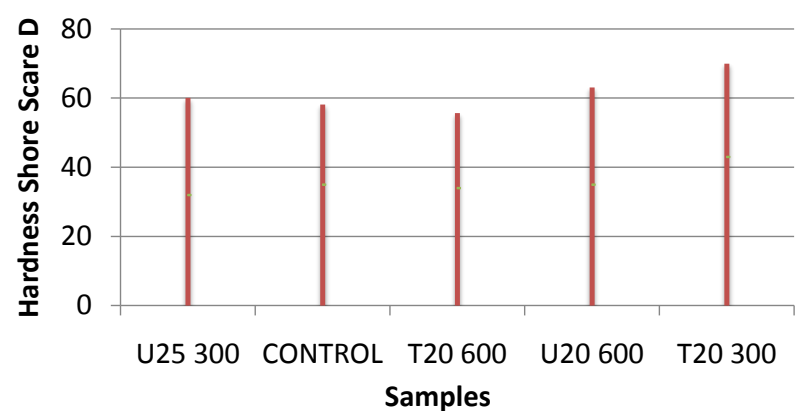

Figure 5. Hardness of GSP-recycled polyethylene composite on Shore scale D.

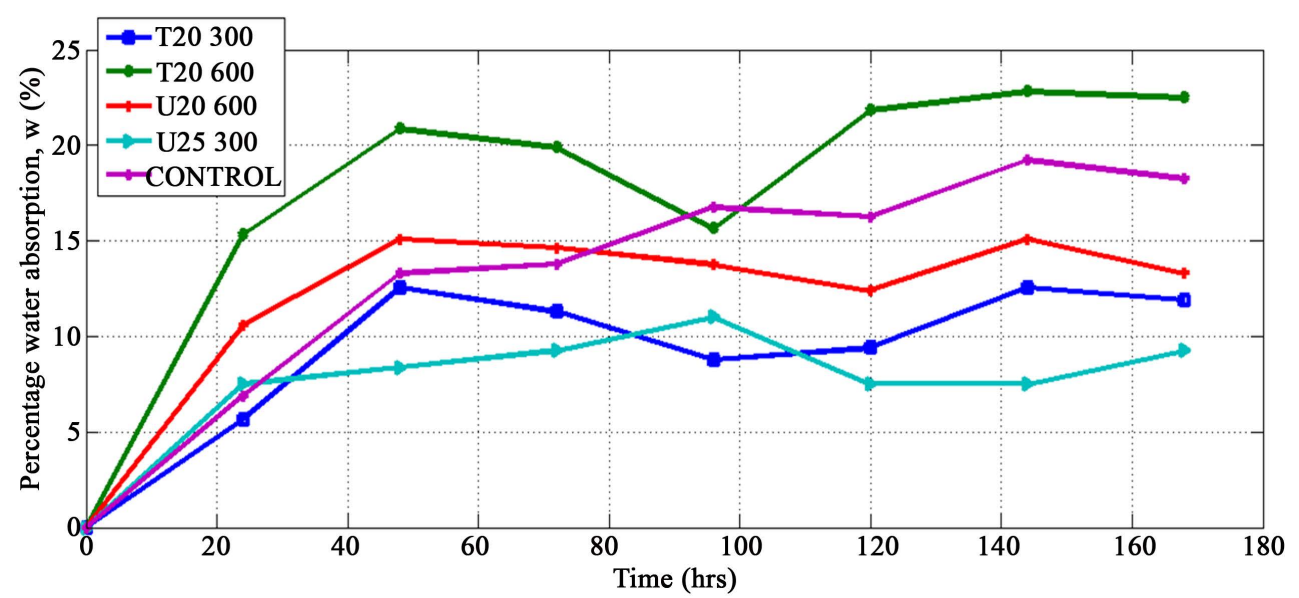

Figure 6. Percentage water absorption of GSP-recycled polyethylene composite. 
control sample have more voids in them as compared to other samples and this explains the high initial rate of water absorption [43], until all the available spaces in the composite are taken over by the water. At saturation, the rate of water absorption remained constant and this occurred between 140 - 160 hours of immersion. Based on the intended application of the material, a lower rate of water absorption is desired implying that voids in the composite should be as minimal as possible as larger voids promote diffusion [44] and higher rate of water absorption [45]. Furthermore, treated samples of smaller particles had lower rates of water absorption, suggesting that combinations of smaller particles and fiber treatment will give rise to lower rate of water absorption and better mechanical properties [46].

\subsection{Biodegradability Test}

Biodegradation of GSP-recycled polyethylene involves four steps: (1) attachment of the microorganism at the surface of the sample (2) growth of microorganism, utilizing the sample as carbon source, (3) primary degradation of the sample and (4) ultimate degradation of the sample.

Figure 7 shows the growth of the fungi (Aspergillus niger) on the surface of GSP-recycled polyethylene composite. The results revealed that there was no growth of fungi on the surface of recycled polyethylene (control sample). After 3 days of commencement of the experiment, there was evidence of growth of fungi on the surface sample containing GSP except the sample containing no GSP (control sample). This growth was equally faster in the treated samples and the growth became equal after two weeks. This initial high growth rate of the fungi on the treated sample could have been caused by the removal of hemicellulose and lignin as a result of treatment, thereby leaving only cellulose in the GSP. This growth of A. niger on the surface of the composite samples suggests that groundnut shell supports the growth of the fungi and that GSP-recycled polyethylene composites have been attacked by the fungi [24]. Therefore, GSP-recycled polyethylene composite is biodegradable. It should be noted that the growth of the fungi as evident in this study is due to the consumption of the modified polyethylene by the microorganisms, the rate of this consumption being extensively influenced by abiotic factors.

\subsection{Characterization}

\subsubsection{FTIR Study}

The FTIR spectra of untreated and treated groundnut shell powder (Figure 8) reveals some important information about their characteristic absorption bands. The mean peaks are located at $3456 \mathrm{~cm}^{-1}$ (stretching of O-H bond), $2926 \mathrm{~cm}^{-1}$ (stretching of C-H) bond, and $1058 \mathrm{~cm}^{-1}$ (stretch ring of glucose). The latter peak is directly connected to the structure of the cellulose and remains unchanged after treatment, thus showing that cellulose is not degraded (Marques et al., 2015). In alkaline-treated GSP, it can be noticed that disappearance of the absorption peaks at $1600 \mathrm{~cm}^{-1}$ corresponding to C-O stretching of hemicellulose and lignin. Stretching in other locations confirmed that most of the hemicellulose and lignin has been removed.

Figure 9 shows the FTIR spectra of GSP-recycled polyethylene composites and the recycled polyethylene.

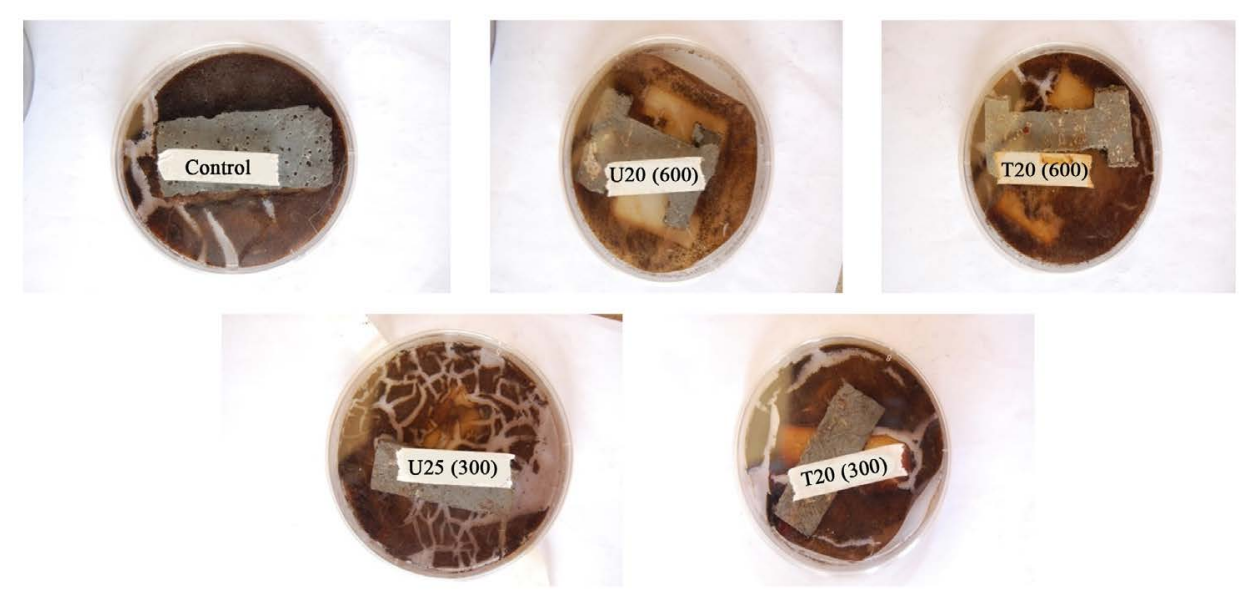

Figure 7. Growth of Aspergillus niger (Fungi) on the GSP-recycled polyethylene composites. 


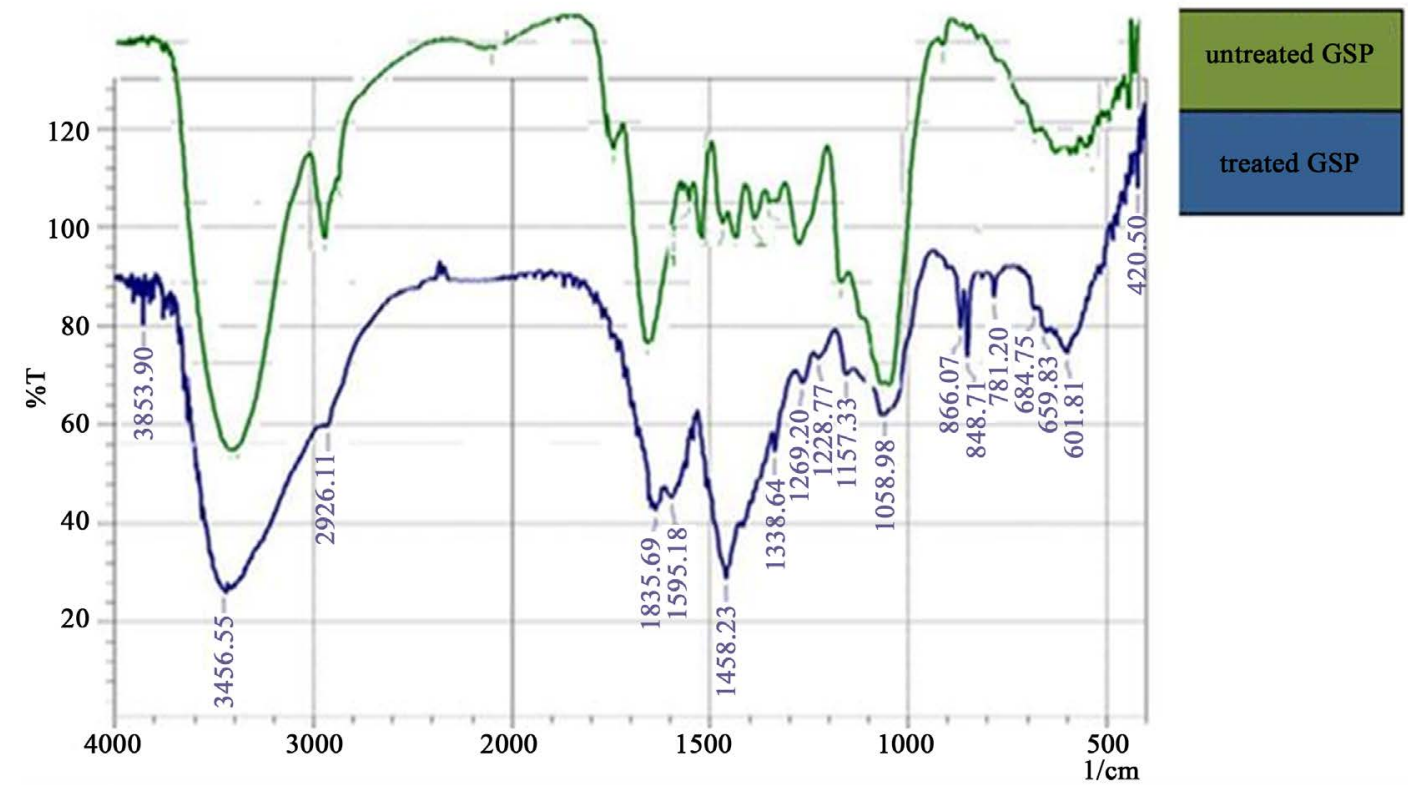

Figure 8. FTIR of treated and untreated GSP.

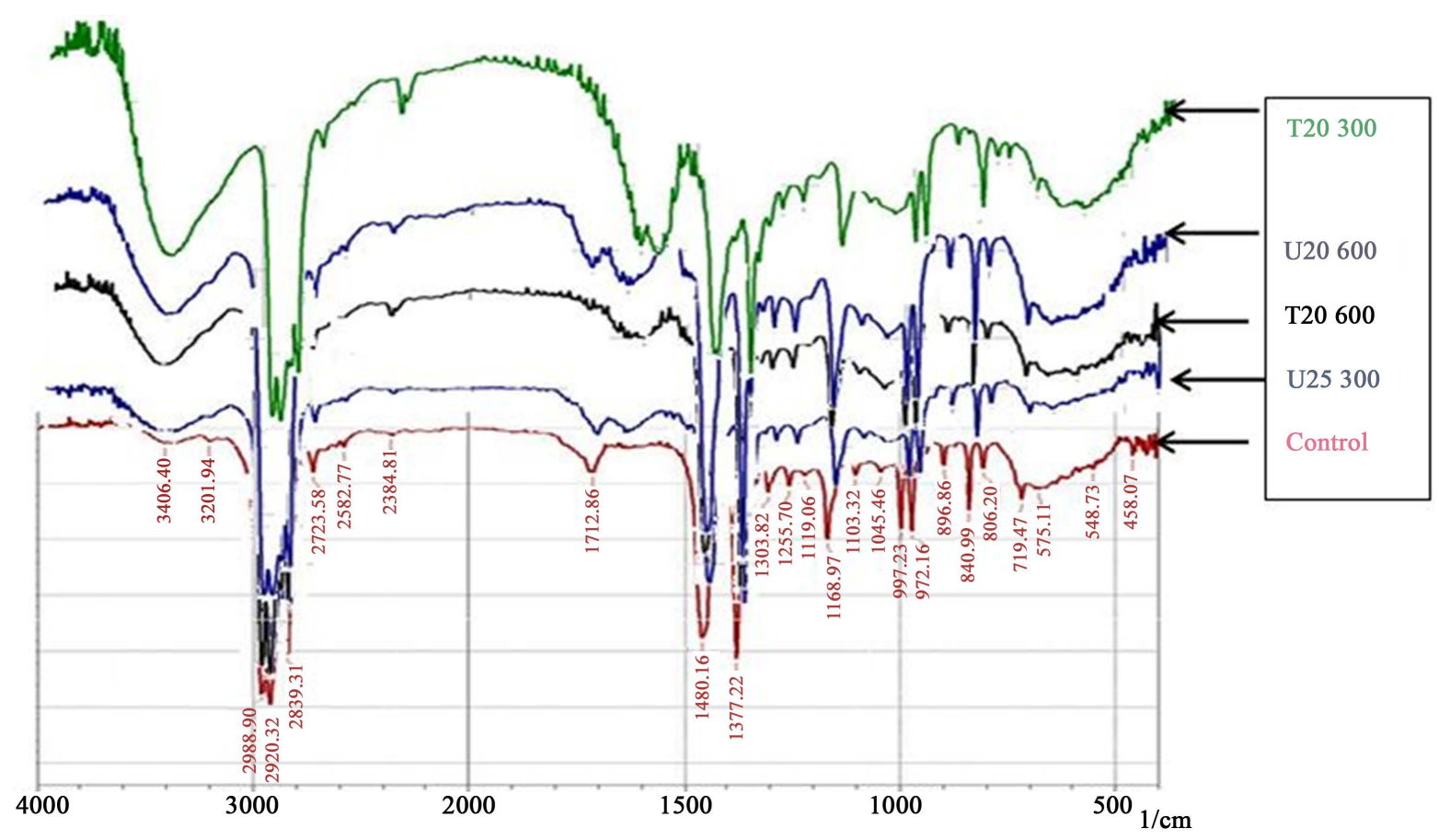

Figure 9. FTIR of GSP-recycled polyethylene composites.

The peaks of treated and untreated GSP-recycled polyethylene composites are similar as the stretching occurs almost at the same position. However, the peaks of the recycled polyethylene (control) sample show a slight difference as peak broadening occurs in the GSP-recycled polyethylene composites. This confirmed the presence of second-phase particles in the recycled polyethylene.

\subsubsection{Scanning Electron Microscopy}

SEM micrographs (Figure 10) reveal the surface morphology of the GSP-recycled polyethylene composites. The SEM evidences why composites with treated GSP fibers show better results in terms of tensile strength, 


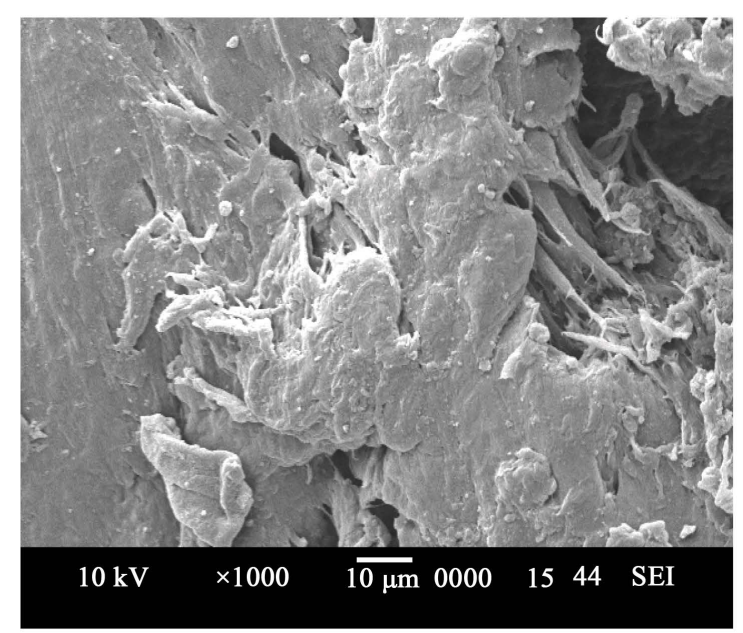

(a)

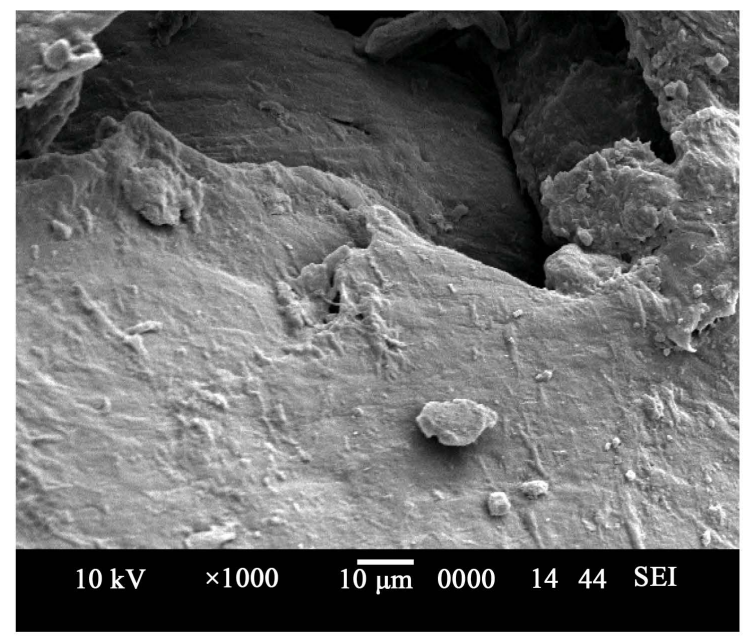

(c)

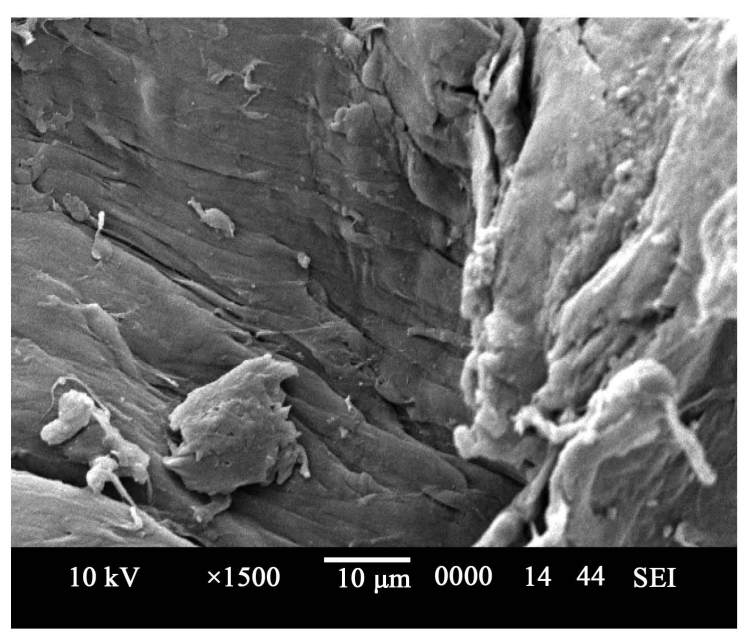

(b)

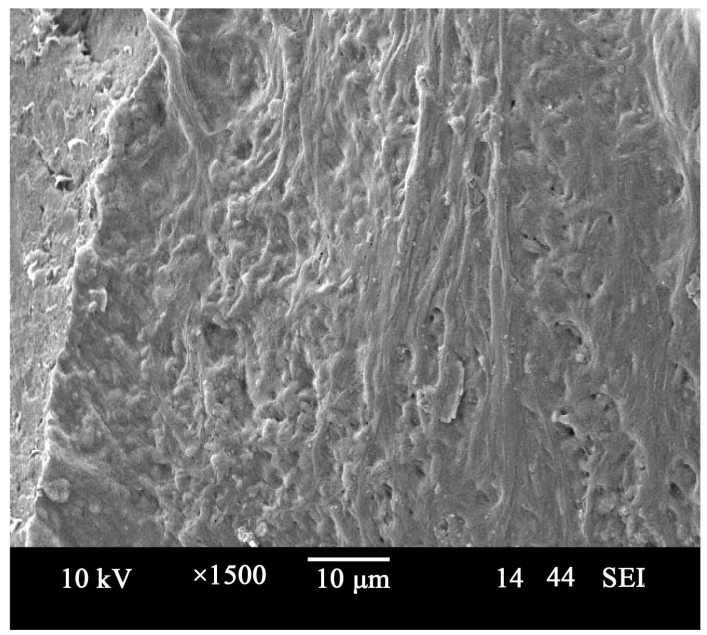

(d)

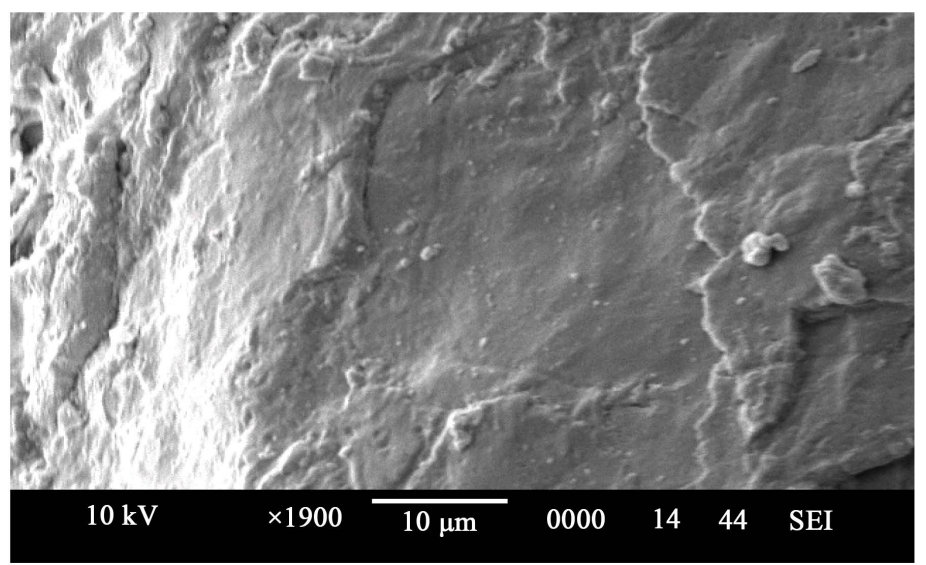

(e)

Figure 10. SEM micrographs with (a) recycled polyethylene at $\times 1000$; (b) T20 300 at $\times 1500$, (c) T20 600 at $\times 1000$; (d) U20 $600 \times 1500$; (e) U25 $300 \times 1900$, at accelerating voltage of $10 \mathrm{KV}$.

hardness and Young modulus than untreated fibers. Presence of voids was observed in the recycled polyethylene of Figure 10(a) with GSP and this explains why the mechanical properties are lower and there is a higher rate of 
water absorption. In Figure 10(b) the SEM images showed that there is uniform dispersion of the treated GSP in the polymer matrix with less agglomeration of the fibers particles. In Figure 10(c) the SEM image is similar to that of Figure 10(b) except that the particle size of GSP is larger. This results in poor interaction between the fibers and polymer matrix as evident in the presence of little voids. In Figure 10(d), the presence of void is conspicuously noticed as a result of the large particle size of the fibers and delamination is possible in this sample due to poor distribution of fibers in the matrix. This explains its poor mechanical properties as compared to the treated and lower particle size GSP. The same scenario can be observed in Figure 10(e) although there is better distribution of GSP due to its smaller particle size leading to the voids being considerably reduced.

Therefore, SEM results indicate that there is better interaction between the treated GSP fibers and the polymer matrix. This confirms that increase in the mechanical properties of treated GSP-recycled polyethylene was as a result of uniform distribution of the fibers in the polyethylene matrix.

\section{Conclusion}

In this work, alkaline treated groundnut shell powder has been shown to improve the mechanical properties of GSP-recycled polyethylene composites, with a treated GSP of 20\% weight fraction (T20 300) recycled polyethylene composite having the highest mechanical properties. This treated sample also has a lower rate of water absorption and this shows that composites produced with alkaline treated GSP and smaller particles are better materials for their intended applications. In addition, the FTIR spectra revealed the absence of some peaks in the alkaline treated GSP and removal of the functional group belonging to lignin and hemicelluloses, thus confirming that the alkaline treatment was successful. Uniform distribution of GSP was observed in the alkaline treated GSP composites as shown by the SEM micrographs and this confirmed that treated GSP had better bonding with the polymer matrix. Evidence of growth of Aspergillus niger (fungi) on the samples suggests that GSP-recycled polyethylene composite is biodegradable. Thus, groundnut shell is a suitable reinforcing filler for recycled polyethylene; providing a valorization platform in addition to addressing environmental challenge.

\section{References}

[1] Yu, J., Sundqvist, B., Tonpheng, B. and Andersson, O. (2014) Thermal Conductivity of Highly Crystallized Polyethylene. Polymer, 55, 195-200. http://dx.doi.org/10.1016/j.polymer.2013.12.001

[2] Anwar, M. and Schilling, T., (2015) Crystallization of Polyethylene: A Molecular Dynamics Simulation Study of the Nucleation and Growth Mechanisms. Polymer, 76, 307-312. http://dx.doi.org/10.1016/j.polymer.2015.08.041

[3] Kurtz, S.M. (2009) UHMWPE Biomaterials Handbook: Ultra High Molecular Weight Polyethylene in Total Joint Replacement and Medical Devices. 2nd Edition, Elsevier, Amsterdam.

[4] Vasile, C. and Pascu, M. (2005) Practical Guide to Polyethylene. Rapra Technology Limited, Shrewsburg.

[5] Ferreira, L.M., Falcao, A.N. and Gil, M.H. (2005) Modification of LDPE Molecular Structure by Gamma Irradiation for Bio Applications. Nuclear Instruments and Methods in Physics Research Section B, 236, 513-520. http://dx.doi.org/10.1016/j.nimb.2005.04.030

[6] Piringer, O.G. and Baner, A.L. (2008) Plastic Packaging: Interactions with Food and Pharmaceuticals. 2nd Edition, Wiley-VCH, Weisheim. http://dx.doi.org/10.1002/9783527621422

[7] Otake, Y., Kobayashi, T., Asabe, H., Murakami, N. and Ono, K. (1995) Biodegradation of Low-Density Polyethylene, Polystylene, Polyvinyl Chloride, and Urea Formalde-Hyde Resin Buried under Soil for over 32 Years. Journal of Applied Polymer Science, 56, 1789-1796. http://dx.doi.org/10.1002/app.1995.070561309

[8] Potts, J.E. and Jelink, H.H.G. (1978) Biodegradation Aspects of Biodegradation \& Stabilization of Polymers. Elsevier, Oxford, New York, 482-483.

[9] Albertsson, A.C., Erlandsson, B., Hakkarainen, M. and Karlsson, S. (1998) Molecular Weight Changes and Polymeric Matrix Changes Correlated with the Formation of Degradation Products in Biodegraded Polyethylene. Journal of Environmental Polymer Degradation, 6, 187-195. http://dx.doi.org/10.1023/A:1021873631162

[10] Volke-Sepulveda, T., Saucedo-Castaneda, G., Gutierrez-Rojas, M., Manzur, A. and Favela-Torres, E. (2002) Thermally Treated Low Density Polyethylene Biodegradation by Penicillium pinophilum and Aspergillus niger. Journal of Applied Polymer Science, 83, 305-314. http://dx.doi.org/10.1002/app.2245

[11] Roy, P.K., Titus, S., Surekha, P., Tulsi, E., Deshmukh, C. and Rajagopal, C. (2008) Degradation of Abiotically Aged LDPE Films Containing Pro-Oxidant by Bacterial Consortium. Polymer Degradation and Stability, 93, 1917-1922. http://dx.doi.org/10.1016/j.polymdegradstab.2008.07.016 
[12] Chatterjee, S., Roy, B., Roy, D. and Banerjee, R. (2010) Enzyme-Mediated Biodegradation of Heat Treated Commercial Polyethylene by Staphylococcal Species. Polymer Degradation and Stability, 95, 195-200. http://dx.doi.org/10.1016/j.polymdegradstab.2009.11.025

[13] Satapathy, S., Chattopadhyay, S., Chakrabarty, K.K., Nag, A., Tiwari, K.N., Tikku, V.K. and Nando, G.B. (2006) Studies on the Effect of Electron Beam Irradiation on Waste Polyethylene and Its Blend with Virgin Polyethylene. Journal of Applied Polymer Science, 101, 715-726. http://dx.doi.org/10.1002/app.23970

[14] Satapathy, S. and Kothapalli, R.V.S., (2015) Influence of Fly Ash Cenospheres on Performance of Coir Fiber-Reinforced Recycled High-Density Polyethylene Biocomposites. Journal of Applied Polymer Science, 132, 42237. http://dx.doi.org/10.1002/app.42237

[15] Cui, Y., Lee, S., Noruziaan, B., Cheung, M. and Tao, J. (2008) Fabrication and Interfacial Modification of Wood/Recycled Plastic Composite Materials. Composite Part A: Applied Science and Manufacturing, 39, 655-661. http://dx.doi.org/10.1016/j.compositesa.2007.10.017

[16] Sommerhuber, P.F., Welling, J. and Krause, A. (2015) Substitution Potentials of Recycled HDPE and Wood Particles from Post-Consumer Packaging Waste in Wood-Plastic Composites. Waste Management, 46, 76-85. http://dx.doi.org/10.1016/j.wasman.2015.09.011

[17] Teuber, L., Militz, H. and Krause, A. (2016) Processing of Wood Plastic Composites: The Influence of Feeding Rate Method and Polymer Melt Rate on Particle Degradation. Journal of Applied Polymer Science, 133, Article ID: 43231. http://dx.doi.org/10.1002/app.43231

[18] Yao, F., Wu, Q., Lei, Y. and Xu, Y. (2008) Rice Straw Fiber-Reinforced High-Density Polyethylene Composite: Effect of Fiber Type and Loading. Industrial Crops and Products, 28, 63-72. http://dx.doi.org/10.1016/j.indcrop.2008.01.007

[19] Favano, S.L., Ganzerli, T.A., De Carvalho Neto, A.G.V., Da Silva, O.R.R.F. and Radovanovic, E. (2010) Chemical, Morphological and Mechanical Analysis of Sisal Fiber-Reinforced Recycled High-Density Polyethylene Composites. eXPRESS Polymer Letters, 4, 465-473. http://dx.doi.org/10.3144/expresspolymlett.2010.59

[20] Fang, H., Zhang, Y., Deng, J. and Rodrigue, D. (2013) Effect of Fiber Treatment on the Water Absorption and Mechanical Properties of Hemp Fiber/Polyethylene Composite. Journal of Applied Polymer Science, 127, 942-949. http://dx.doi.org/10.1002/app.37871

[21] Vieyra, H., Martin-Martinez, E.S., Juarez, E., Figueroa-Lopez, U. and Aguilar-Mendez, M.A. (2015) Biodegradation Process of a Blend of Thermoplastic Unripe Banana Flour-Polyethylene under Composting: Identification of the Biodegrading Agent. Journal of Applied Polymer Science, 132, Article ID: 42258. http://dx.doi.org/10.1002/app.42258

[22] Naghmouchi, I., Mutje, P. and Boufi, S. (2015) Olive Stones Flour as Reinforcement in Polypropylene Composites: A Step Forward in the Valorization of the Solid Waste from the Olive Oil Industry. Industrial Crops and Products, 72, 183-191. http://dx.doi.org/10.1016/j.indcrop.2014.11.051

[23] Bledzki, A.K., Franciszczak, P., Osman, Z. and Elbadawi, M. (2015) Polypropylene Biocomposites Reinforced with Softwood, Abaca, Jute, and Kenaf Fibers. Industrial Crops and Products, 70, 91-99. http://dx.doi.org/10.1016/j.indcrop.2015.03.013

[24] Sunilkumar, M., Francis, T., Thomas, E. and Sujith, A. (2012) Low Density Polyethylene-Chitosan Composite: A Study Based on Biodegradation. Chemical Engineering Journal, 204-206, 114-124. http://dx.doi.org/10.1016/j.cej.2012.07.058

[25] Taru, V.B., Kyagya, I.Z., Mshelia, S.I. and Adebayo, E.F. (2008) Economic Efficiency of Resource Use in Groundnut Production in Adamawa State of Nigeria. World Journal of Agricultural Sciences, 4, 896-900.

[26] Ibrahim, U., Ayinde, B.T., Dauda, H. and Mukhtar, A.A. (2013) Socio-Economic Factors Affecting Groundnut Production in Sabongari Local Government of Kaduna State, Nigeria. International Journal of Food and Agricultural Economy, 1, 41-48.

[27] Alaneme, K.K., Bodunrin, M.O. and Awe, A.A. (2016) Microstructure, Mechanical and Fracture Properties of Groundnut Shell Ash and Silicon Carbide Dispersion Strengthened Aluminium Matrix Composites. Journal of King Saud University-Engineering Sciences, in Press. http://dx.doi.org/10.1016/j.jksues.2016.01.001

[28] Kalia, S., Kaith, B.S. and Kaur, I. (2009) Pretreatments of Natural Fibers and Their Application as Reinforcing Material in Polymer Composites: A Review. Polymer Engineering and Science, 49, 1253-1272. http://dx.doi.org/10.1002/pen.21328

[29] John, M.J. and Anandjiwala, R.D. (2008) Recent Developments in Chemical Modification and Characterization of Natural Fiber-Reinforced Composites. Polymer Composites, 29, 187-207. http://dx.doi.org/10.1002/pc.20461

[30] Li, X., Tabil, L.G. and Panigrahi, S. (2007) Chemical Treatments of Natural Fiber for Use in Natural Fiber-Reinforced Composites: A Review. Journal of Polymers and the Environment, 15, 25-33. http://dx.doi.org/10.1007/s10924-006-0042-3

[31] Lee, K., Delille, A. and Bismarck, A. (2011) Greener Surface Treatments of Plant Fibres for the Production of Renew- 
able Composite Materials, in: Kalia, S., Kaith, B.S. and Kaur, I., Eds., Cellulose Fibers: Bio- and Nano-Polymer Composites, Springer-Verlag, Berlin, 155-178. http://dx.doi.org/10.1007/978-3-642-17370-7_6

[32] Schutze, A., Yeong, J.Y., Babayan, S.E., Park, J., Selwyn, G.S. and Hicks, R.F. (1998) The Atmospheric Pressure Plasma Jet: A Review and Comparison to Other Plasma Sources. IEEE Transactions on Plasma Science, 26, 16851694. http://dx.doi.org/10.1109/27.747887

[33] Bogoeva-Gaceva, G., Avella, M., Malinconico, M., Buzarovska, A., Grozdanov, A., Gentile, G. and Errico, M.E. (2007) Natural Fiber Eco-Composites. Polymer Composites, 28, 98-107. http://dx.doi.org/10.1002/pc.20270

[34] Mohanty, A.K., Khan, M.A. and Hinrichsen, G. (2000) Surface Modification of Jute and Its Influence on Performance of Biodegradable Jute-Fabric/Biopol Composites. Composite Science and Technology, 60, 1115-1124. http://dx.doi.org/10.1016/S0266-3538(00)00012-9

[35] Marques, M.V., Melo, R.P., Araujo, R.S., Lunz, J.N. and Aguiar, V.O. (2015) Improvement of Mechanical Properties of Natural Fiber-Polyethylene Composites Using Successive Alkaline Treatment. Journal of Applied Polymer Science, 132, Article ID: 41710.

[36] Sareena, C., Ramesan, M.T. and Purushothaman, E. (2012) Utilization of Peanut Shell Powder as a Novel Filler in Natural Rubber. Journal of Applied Polymer Science, 125, 2322-2334. http://dx.doi.org/10.1002/app.36468

[37] Deo, C. and Acharya, S.K. (2010) Effect of Moisture Absorption on Mechanical Properties of Chopped Natural Fiber Reinforced Epoxy Composite. Journal of Reinforced Plastics and Composites, 29, 2513-2521. http://dx.doi.org/10.1177/0731684409353352

[38] Tajvidi, M. and Azad, F.J. (2009) Effect of Particle Size, Fiber Content and Compatibilizer on the Long Term Water Absorption and Thickness Swelling Behavior of Reed Flour/Polypropylene Composite. Journal of Reinforced Plastics and Composites, 28, 2341-2351. http://dx.doi.org/10.1177/0731684408091954

[39] Kim, H.J. and Seo, D.W. (2006) Effect of Water Absorption Fatigue on Mechanical Properties of Sisal Textile-Reinforced Composites. International Journal of Fatigue, 28, 1307-1314. http://dx.doi.org/10.1016/j.ijfatigue.2006.02.018

[40] Maskavs, M., Kalnins, M., Reihmane, S., Laka, M. and Chernyavskaya, S. (1999) Effect of Water Sorption on Some Mechanical Parameters of Composite Systems Based on Low-Density Polyethylene and Microcrystalline Cellulose. Mechanics of Composite Materials, 35, 55-62. http://dx.doi.org/10.1007/BF02260812

[41] Islam, M.R., Gupta, A., Rivai, M., Beg, M.D.H. and Mina, M.F. (2016) Effects of Fiber-Surface Treatment on the Properties of Hybrid Composites Prepared from Oil Palm Empty Fruit Bunch Fibers, Glass Fibers, and Recycled Polypropylene. Journal of Applied Polymer Science, 133, Article ID: 43049. http://dx.doi.org/10.1002/app.43049

[42] Ellyin, F. and Maser, R. (2004) Environmental Effects on the Mechanical Properties of Glass-Fiber Epoxy Composite Tubular Specimens. Composite Science and Technology, 64, 1863-1874. http://dx.doi.org/10.1016/j.compscitech.2004.01.017

[43] Zhang, S.Y., Zhang, Y., Bousmina, M., Sain, M. and Choi, M. (2007) Effects of Raw Fiber Materials, Fiber Content, and Coupling Agent Content on Selected Properties Polyethylene/Wood Fiber Composites. Polymer Engineering and Science, 47, 1678-1687. http://dx.doi.org/10.1002/pen.20854

[44] Askeland, D.R. and Phule, P.P. (2003) The Science and Engineering of Materials. 4th Edition, Brooks/Cole Publishing/Thompson Learning, USA.

[45] Esnaashari, C., Khorasani, S.N., Entezam, M. and Khalili, S. (2013) Mechanical and Water Absorption Properties of Sawdust-Low Density Polyethylene Nanocomposites. Journal of Applied Polymer Science, 127, 1295-1300. http://dx.doi.org/10.1002/app.37624

[46] Gassan, J. and Bledzki, A.K. (1997) The Influence of Fiber-Surface Treatment on the Mechanical Properties of JutePolypropylene Composites, Composites Part A: Applied Science and Manufacturing, 28, 1001-1005.

http://dx.doi.org/10.1016/S1359-835X(97)00042-0 